\title{
@2LOCUS
}

Seção Livre

bttp://dx.doi.org/10.34019/2594-8296.2020.v26.27812

\section{A Microstoria Italiana e os desafios biográficos na historiografia recente (1980-2000)}

\section{Italian Microstoria and biographical challenges in recent historiography (1980-2000) \\ La Microhistoria Italiana y los desafios biográficos en la reciente historiografía (1980- 2000)}

\author{
Deivy Ferreira Carneiro* \\ https:/ / orcid.org/0000-0002-5285-7693
}

RESUMO: Pretende-se investigar alguns dos trabalhos e reflexões produzidas por historiadores ligados à micro-história italiana em relação à escrita biográfica e seus desafios. Examinaremos como alguns micro-historiadores se posicionaram, sobretudo no debate biográfico dos anos 1980-2000, e analisaremos como os trabalhos em questão avançaram para além da perspectiva denominada "Biografia Modal". De maneira geral, analisaremos como a biografia foi pensada e desenvolvida pela historiadora Simona Cerutti em seu livro de 2012 e observamos como Maurizio Gribaudi pensa e realiza o estudo de trajetórias individuais em seu artigo Percorsi individuali ed evoluzione storica: quattro percorsi operai attraverso la Francia dell'ottocento, publicado na revista Quaderni Storici em 2001.

Palavras-chave: Micro-história italiana. Biografia. Historiografia.

ABSTRACT: This article aims to analyze some of the main works produced by historians linked to the Italian microhistory in relation to biographical writing and its challenges. We will examine how some micro historians have positioned themselves in the biographical debate of the years 1980-2000, as well as analyze how the works produced by these researchers developed and advanced beyond the Modal biography perspective. In a general way, we will analyze how the biography was thought and developed by the historian Simona Cerutti in her last book (2012)

\footnotetext{
* Professor do Instituto de História da Universidade Federal de Uberlândia. Mestre (2004) e doutor (2008) pela Universidade Federal do Rio de Janeiro. Pós-doutor pela Université Paris 1 - Panthéon/Sorbonne (2013). Pesquisador visitante no LaDéHis da École de Hautes Études em Sciences Sociales (2019). É autor de: História, Violência e Criminalidade: reflexões temáticas e narrativas regionais. Uberlândia: EDUFU, 2015 e de Uma Justiça que Seduz?? Ofensas verbais e conflitos comunitários em Minas Gerais (1854-1941). São Paulo: Paco Editorial, 2019; além de vários artigos e capítulos de livros. Concentra suas pesquisas em História da Violência, História da Criminalidade e Microstoria italiana. E-mail: deivycarneiro@gmail.com
} 
and we observe how Maurizio Gribaudi thinks and conducts the study of individual trajectories in his article, Percorsi individuali ed evolurione storica: quattro percorsi operai attraverso la Francia dell'ottocento published in Quaderni Storici magazine in 2001.

Keywords: Italian microhistory. Biography. Historiography.

RESUMEN: Pretendemos investigar algunas de las obras y reflexiones producidas por historiadores vinculados a la microhistoria italiana en relación con la escritura biográfica y sus retos. Examinaremos cómo algunos microhistoriadores se han posicionado, especialmente en el debate biográfico de los años 1980-2000, y analizaremos cómo el trabajo en cuestión avanzó más allá de la perspectiva llamada "biografía modal". En general, analizaremos cómo la biografía fue concebida y desarrollada por la historiadora Simona Cerutti en su libro de 2012 y observamos como Maurizio Gribaudi Piensa y lleva a cabo el estudio de trayectorias individuales en su artículo Percorsi individuali ed evoluzione storica: quattro percorsi operai attraverso la Francia dell'ottocento, publicado en la revista Quaderni Storici en 2001.

Palabras clave: Microhistoria Italiana. Biografía. Historiografía.

\section{Como citar este artigo:}

Carneiro, Deivy Ferreira. "A Microstoria italiana e os desafios biográficos na historiografia recente (1980-2000)". Locus: Revista de História, 26, n. 1 (2020): 211-234.

\section{Introdução}

Para o historiador francês François Dosse, apesar da escrita da vida não ser um horizonte plenamente inacessível, todas as gerações de historiadores e cientistas sociais aceitaram a aposta biográfica mobilizando o conjunto de instrumentos que tinham à sua disposição nos mais variados momentos históricos. Se, a princípio, as biografias (ou vitae) eram concebidas como exemplares de um gênero discursivo com forte apelo moral e voltado para a promoção de exemplos de virtude, com o tempo um discurso de autenticidade, de verossimilhança e de verdade passou a tomar conta e a direcionar o trabalho do biógrafo. Todavia, por mais que o discurso de verdade fosse uma meta, permaneceu na produção biográfica uma forte tensão entre ficção e realidade histórica (Dosse 2009, 11-12).

A partir dos anos 1980, a discussão sobre o status da biografia e sua relação com a história ressurgiu com intensidade no cenário historiográfico internacional. Nesse contexto, alguns autores ligados à micro-história italiana aproveitaram a oportunidade para discutir suas perspectivas analíticas sobre as experiências individuais, grupais e de classe. Além disso, 
questionaram em seus trabalhos empíricos e teóricos o modelo da escrita biográfica heroica e, como veremos, a coerência de elementos mecânicos presentes naquilo que Dosse chamou de “biografia modal” (Dosse 2009, 195-228).

Historiadores como Simona Cerutti, Maurizio Gribaudi, Giovanni Levi, Edoardo Grendi e Sabina Loriga questionaram o princípio da narrativa linear permeada pelo tropo da ironia nas biografias tradicionais, inserindo a trajetória de vida dos atores sociais em um espaço relacional e interdependente. Mais especificamente, apresentaram em seus trabalhos uma perspectiva em que o foco biográfico, que faz parte da proposta original da micro-história e de sua contribuição empírica, acomoda os atores sociais e as instituições que criaram as estruturas que contribuíram para o florescimento dessas interações e que geraram a maior parte dos registros documentais que sedimentaram a memória dessas mesmas interações (Trivellato 2011, 584-585).

Dessa maneira, ao inserir o biografado nas suas redes de relações, os trabalhos microhistóricos possibilitam a observação de comportamentos individuais (complexos, desconexos e contraditórios) em relação às ações e crenças individuais de parentes, vizinhos, conhecidos e superiores, oferecendo um meio mais denso para examinarmos a estrutura e as margens de manobras do espaço social em que os atores estão inseridos (Carneiro 2018a).

Desta feita, podemos considerar este artigo uma continuação e uma ampliação das discussões realizadas em um texto anterior sobre a mesma temática, mas com conclusões mais amplas e, ao mesmo tempo, pormenorizadas. A abordagem biográfica apontada por autores ligados à micro-história pode nos ajudar a esclarecer as tentativas de reconstrução das ações, experimentos, hesitações, falhas, planos intencionais e estratégias bem ou malsucedidas e do papel desempenhado pelos atores sociais (Ago 2004, 43).

Para atingir esses objetivos, o artigo foi dividido em três partes. Na primeira, examinamos como alguns micro-historiadores se posicionaram, direta e indiretamente, no debate biográfico dos anos 1980 e 1990, dentro daquilo que François Dosse chamou de "Biografia Modal". Além disso, analisamos como os trabalhos produzidos por estes pesquisadores se desenvolveram e avançaram para além desta perspectiva biográfica. Num segundo momento, investigamos como a biografia foi pensada e desenvolvida na obra "Étrangers: étude d'une condition d'incertitude dans une société d'Ancien Régime", publicada em 2012 pela historiadora Simona Cerutti, na qual a autora reconstrói, dentre outras coisas, a biografia de um alfaiate otomano radicado em Turim. Por fim, na terceira parte, observamos como Maurizio Gribaudi pensa e realiza o estudo de trajetórias individuais em seu artigo Percorsi individuali ed evoluzione storica: quattro percorsi operai attraverso la Francia dell'ottocento, publicado na revista Quaderni Storici em 2001. 


\section{A resposta da micro-história italiana aos desafios biográficos}

Antes de iniciarmos, gostaria de ressaltar que meu objetivo não é fazer uma discussão aprofundada sobre a questão biográfica e suas problemáticas, nem mesmo me deter em sua trajetória histórica, o que certamente foi feito com bastante perspicácia por François Dosse (Dosse 2009), Jacques Revel (Revel 2010, 235-248), Sabina Loriga (Loriga 1998), dentre outros. Meu objetivo é analisar, mesmo que brevemente, as respostas, diretas e indiretas, que alguns historiadores italianos deram a essa querela, em específico a crítica produzida por eles em trabalhos empíricos e de feição mais teórica, ao modelo modal de biografia, bem como as críticas que Pierre Bourdieu fez ao gênero em seu texto intitulado "A ilusão Biográfica".

De acordo com Dosse, a biografia modal corresponderia tanto a um momento histórico quanto a uma forma de abordagem do gênero. Por meio de uma figura específica, a biografia modal visaria o tipo idealizado que ela encarna. Por outras palavras, nesse modelo biográfico a análise do sujeito histórico somente teria valor na medida em que ilustrasse o coletivo. O singular seria um caminho de entrada no geral e o sujeito biografado visto, inconscientemente talvez, como um tipo ideal weberiano do seu universo cultural; universo este que serviria de pano de fundo para a construção da vida registrada pelo historiador-biógrafo.

Trata-se de algo muito diferente do modelo biográfico heroico, intimamente ligado à chamada Historia Magistra Vitae, tópica ciceroniana por meio da qual se buscava a construção de um modelo moral edificante e instrutivo capaz de transmitir valores às gerações futuras. As vitae inscrevem-se, durante um longo período, no respeito à tradição, algo que foi concebido na Antiguidade e perdurou com o Cristianismo, nos valores religiosos que se difundem tomando por modelo as vidas exemplares, sobretudo dos santos (Dosse 2009, 123-135).

Ainda de acordo com Dosse, talvez seja justo afirmar que vários historiadores ligados à terceira geração dos Annales acabaram produzindo, dentro do campo da história das mentalidades, biografias modais. Historiadores como George Duby, Michel Vovelle e mesmo Lucien Febvre, membro fundador dos Annales, ao produzirem as biografias de Guilherme Marechal, Rabelais e Lutero, acabaram valorizando análises dicotômicas, privilegiando o caráter impessoal que regularia as práticas sociais. Ao atribuir a uma dada sociedade uma mentalidade comum, esses historiadores correram o sério risco de produzir generalizações abusivas e minimizar as múltiplas variantes individuais (Dosse 2009, 207).

Um dos textos seminais que criticou as perspectivas acima referidas foi publicado por Giovanni Levi, um dos principais micro-historiadores italianos que buscou inspiração na antropologia social inglesa (Levi 1996). Apesar de já termos discutido esse trabalho em um artigo, 
é importante ressaltar que Levi, dentre outras coisas, questionou a narrativa da biografia heroica, por apresentar um sujeito agindo de forma sempre coerente, estável e racional. Todavia, é importante notar que a discussão produzida por Giovanni Levi não ficou apenas no campo teórico: seu principal livro aborda empiricamente as questões apontadas acima (Carneiro 2018a, 41).

Por meio da análise da trajetória de um padre exorcista que atuava no Piemonte do século XVII e de todos os habitantes da aldeia de Santena, Levi conseguiu analisar um processo histórico cuja dinâmica colocava em jogo configurações sociais complexas, imprevisíveis e não lineares. Adotando uma técnica intensiva de reconstrução dos eventos biográficos dos membros dessa aldeia, Levi acessou mecanismos de ordem geral. Se seu ponto de partida foi a análise dos itinerários individuais, a observação dos comportamentos e das estratégias revelou cadeias de dependências causais que ligavam esferas comumente concebidas como separadas (Levi 2000).

Ao deslocar a causalidade dos fenômenos para os indivíduos e para os mecanismos interativos, Levi reconstruiu as dinâmicas que seguiam as referências simbólicas e os espaços de relações que foram pertinentes nas diversas e sucessivas perspectivas individuais. Ao analisar a ação social dos indivíduos e das famílias, dos camponeses e sacerdotes, dos grupos e suas estratégias, Levi fez aparecer não apenas os elementos que pesavam nas escolhas dos atores, mas também um dinâmico mercado de terras altamente personalizado e o surgimento de uma nova configuração do Estado Moderno europeu.

Fazendo uso de fontes paroquiais, o historiador italiano conseguiu inscrever as trajetórias do exorcista e de sua comunidade dentro de uma rede maior de parentesco e vizinhança, rede esta ampliada graças aos testamentos, atas notariais, contratos de meação etc. Isso lhe permitiu alcançar outros espaços, incluindo outros indivíduos e outras figuras sociais. Desta feita, as estratégias de indivíduos e famílias foram reconstruídas a partir dos laços conservados nestas fontes, o que permite a generalização do modelo, do caso individual ao contexto: laços e formas de parentesco semelhantes sugerem experiências e mecanismos análogos (Gribaudi 1998, 135).

É importante ressaltar que, apesar ter sido talvez o primeiro historiador da geração fundadora da micro-história a discutir a biografia e aplicar em seus trabalhos sua própria concepção de fazer biográfico, Giovanni Levi evidentemente não foi o único. Considerado por todos os principais analistas da micro-história como o criador desta corrente historiográfica e seu mais precoce teorizador, Edoardo Grendi talvez seja o menos conhecido dentre eles. Ao longo de sua carreira, dialogou - muitas vezes de maneira polêmica - com Eric Hobsbawm, Natalie Zemon Davis, E. P. Thompson, Karl Polanyi e Clifford Geertz, e com os estudiosos mais próximos da Escola dos Annales (Giulli 2017, 153). 
A redução de escala de observação gerou no trabalho de Grendi uma referência constante à história local, mas de modo algum uma história local autorreferencial, já que manteve diálogo com o debate historiográfico internacional; um debate que, no que diz respeito à Gênova e sua República, levou-o a questionar o paradigma braudeliano e macroscópico do "virtualismo" financeiro genovês que, todavia, de acordo com Grendi, não tinha sido capaz de atribuir a importância correta ao verdadeiro contexto sociopolítico daquela República (Giulli 2017, 149).

Os seus inúmeros trabalhos sobre Gênova acabaram aproximando-o da biografia histórica - tema que nos interessa nesse artigo - e seu último livro trata de uma biografia coletiva da família Balbi (Grendi 1997), uma das mais importantes da aristocracia de Gênova. Ao contrário de Levi e de Sabina Loriga, Grendi não produziu uma ampla reflexão teórica sobre o status da biografia. A biografia coletiva produzida por ele foi inteiramente baseada na análise morfológica das práticas sociais e das experiências culturais da família Balbi, com o objetivo de propor um modelo de referência mais amplo para o estudo da sociedade aristocrática lígure na Idade Moderna, aproximando-se metodologicamente da análise produzida por Levi em seu livro A Herança Imaterial (Giulli 2017, 150).

Após mapear e reconstruir os fatos que tinham levado os Balbi até o ápice das atividades comerciais e financeiras da Europa, Grendi investigou, assim como um antropólogo em trabalho de campo, o estilo de vida dessa família. Nessa etapa da sua pesquisa percebemos claramente a perspectiva micro-histórica sendo utilizada com maestria para produzir um trabalho de biografia coletiva: servindo-se de uma série heterogênea de fontes arquivísticas, de tipo público e privado, não apenas registros fiscais, escrituras notariais e atos judiciários, mas também inventários de bibliotecas e de obras de arte, a escala reduzida é percebida como um novo local de experimentação, mas sem deixar de explicar os processos globais. Não há a renúncia do macro, mas sim uma tentativa de enriquecê-lo (Grendi 1997, 95-133).

Já que a análise macro tende a ser extremamente generalizante, pouco empírica e muito retórica, Grendi conseguiu descrever nessa biografia coletiva as estruturas sociais sem perder o que há de mais fundamental nas interações sociais. Ele mostrou claramente ao leitor que, apesar das estruturas, os atores sociais analisados possuíam uma liberdade de ação, uma margem de manobra. O historiador italiano percebeu que todas as ações que construíam as normas sociais eram fruto de escolhas, negociações e estratégias dos atores sociais, sem considerar, evidentemente, os membros da família Balbi como hiper-racionais.

A partir dessa forma de análise, uma nova concepção de contexto foi concebida: ao invés de ser retratado como o pano de fundo cultural, social e político que determinaria o comportamento individual, o que, de alguma maneira, aparece nas biografias modais, o contexto 
passou a ser encarado como algo heterogêneo e fraturado. Sendo assim, as normas sociais são criadas nas interações e vivenciadas de formas distintas pelos grupos sociais, fazendo com que o mesmo processo social seja vivenciado diferentemente por homens, mulheres, camponeses, operários e, no caso, aristocratas.

Logo, Grendi conseguiu apresentar um perfil civil da aristocracia genovesa percebida como sistema cultural no qual se destacavam, contudo, diferentes experiências individuais e coletivas. É importante ressaltar que não apenas os homens dessa família tiveram espaço na biografia coletiva analisada. No último capítulo, Grendi analisa as mulheres da família Balbi, propondo um quadro original da componente feminina dessa família e do seu papel específico.

Por fim, devemos retomar o fio condutor da análise que propomos do fazer biográfico de Grendi: a análise morfológica de práticas, experiências e comportamentos apresentada nesse livro refletiu claramente sua perspectiva micro-histórica. Nessa pesquisa ele consegue muito mais do que produzir a descrição mecânica, linear, irônica e cronológica de uma família de aristocratas genoveses. Podemos ver em sua obra uma biografia que, em muito, supera a descrição da biografia modal: na verdade acaba sendo de fato uma crítica a esta. No livro em questão temos um ótimo ponto de partida para tentar utilizar o método microanalítico em perspectiva transnacional e para relacionar a micro-história local (qualitativa e individual) com a macrohistória global (quantitativa e serial) (Giulli 2017, 150).

A partir do que afirmamos, poder-se-ia questionar se Giovanni Levi e Edoardo Grendi, na prática, não teriam suas pesquisas enquadradas naquilo que Dosse chamou de biografia modal? $\mathrm{Na}$ verdade, os usos da biografia recuperados ou adotados pelos micro-historiadores escapam de um modelo simplista de ilustrar um contexto por meio do resgate de uma vida. Evocando algo próximo à noção de tipo ideal weberiana, a biografia modal só tem validade como uma ilustração de comportamentos gerais. Nada mais distante do trabalho empírico de ambos: para eles e para os demais micro-historiadores, não se trata de inserir condutas num comportamento padrão, mas de interpretar as vicissitudes biográficas à luz de um contexto que as tornem possíveis e, portanto, normais (Levi 1996).

Nesse sentido, a proposta biográfica da micro-história se afastaria dos estudos modais, como o Rabelais de Lucien Febvre, que revelaria em seus comportamentos não a sua singularidade, mas o outillage mental de sua época; ou a biografia de Lutero escrita também por Febvre, na qual o reformador alemão só teria pertinência quando confrontado com o universo mental da Alemanha do século XVI (Febvre 2009 e 2012). É o caso, também, da biografia de Guilherme Marechal escrita por George Duby, na qual o guerreiro medieval interessa, sobretudo, como sujeito representativo do universo mental da cavalaria em fins do século XII e início do 
século XIII, momento no qual esse universo entra em declínio (Duby 2002); e da análise de trajetória do burguês Joseph Sec, escrita por Michel Vovelle, na qual o itinerário da personagem principal serve para dar conta de toda uma categoria social, neste caso, da burguesia provinciana.

Apesar de tais trabalhos de biografia modal terem o mérito de conservar a tensão entre a coerência de um destino individual e sua ancoragem na sociedade, devemos nos atentar, como ressaltou Levi, que nas análises supracitadas o contexto acabou sendo descrito, em alguns momentos, como algo rígido e coerente, servindo como pano de fundo imóvel para explicar a vida do biografado. De acordo com ele, nesse modelo biográfico, os destinos individuais seriam inseridos em um contexto, mas não atuariam sobre ele e nem o modificariam (Dosse 2009, 222). O contexto serviria, então, apenas para preencher lacunas documentais da biografia. Teríamos aquilo que Loriga apresentou como biografia sanduíche: uma fatia de contexto, um pouco de biografia, uma fatia de contexto e assim por diante (Loriga 1998, 249).

Além daquilo que chamamos de crítica à questão modal, os micro-historiadores buscaram também, de alguma maneira, responder às questões levantadas por Pierre Bourdieu sobre a biografia, ainda nos anos 1980. Em um artigo publicado em 1986, o sociólogo francês, ao contestar toda a ideia de historicidade linear e cronológica do sujeito, acusa a biografia de ser uma grande ilusão (Bourdieu 2006). Bourdieu ataca sobretudo a ideia presente, de continuidade e de um telos carregado de linearidade subjacente. Apesar de ter razão nessa questão, Bourdieu, à moda estruturalista, nega qualquer pertinência do nome próprio, já que, para ele, o sujeito seria o que ele chama de uma "entidade não pertinente". Assim, a biografia não apresentaria qualquer razão para receber a confiança das ciências sociais (Dosse 2009, 208-9).

Sabina Loriga acabou respondendo, de forma direta e indireta, a essas questões. Em uma entrevista recente, a historiadora italiana afirmou que seu interesse pela biografia ou, mais exatamente, pela história biográfica, estaria estreitamente ligado às suas pesquisas mais antigas. Em sua tese de doutorado, ao estudar o exército piemontês no século XVIII, seu esforço essencial foi reconstituir a realidade institucional a partir de diferentes versões individuais. Por meio dessa experiência de pesquisa, a autora iniciou uma reflexão mais aprofundada sobre a temática biográfica na história.

Duas questões em particular marcaram suas reflexões: quando nos concentramos sobre uma biografia, nós estabelecemos, de uma forma mais ou menos consciente, os elementos e as mudanças significativas de sua vida: quais são os critérios que nós utilizamos para avaliar o peso dos fatos históricos, das práticas sociais, das relações emocionais? A segunda questão visaria às possibilidades de apreender a dinâmica histórica global através de uma perspectiva biográfica, fundada sobre a análise das experiências individuais (Schmidt 2003, 17). 
Ainda nos anos 1990, ela começou a examinar uma reflexão extremamente rica, que se desenvolveu ao longo do século XIX, sobre a história biográfica: nas primeiras décadas desse século, a biografia estaria, em parte, ligada à reflexão sobre a nação; no final desse mesmo século, no entanto, ela faria parte de uma discussão mais ampla e também mais dolorosa sobre o estatuto epistemológico das ciências humanas. Loriga examinou então um núcleo conjunto de autores: Thomas Carlyle, Jacob Burckhardt, Leon Tolstoi, Eduard Meyer, Otto Hintze e Wilhelm Dilthey. Para ela, não havia uma coerência estrita entre seus pensamentos, mas a confluência de ao menos duas ideias importantes.

Em primeiro lugar, acreditavam que o mundo histórico é um mundo de produção, de criação, e que esta qualidade não tem seu fundamento em um princípio absoluto, transcendente ou imanente à ação humana, mas na ação recíproca dos indivíduos. A historiadora italiana pôde afirmar, então, que esses autores não pensam a sociedade como uma totalidade independente (um sistema ou uma estrutura impessoal), mas como uma obra comum: a vida social seria o agregado de todas as vidas individuais. Um segundo ponto em comum entre eles é que recusam a ideia de reduzir os fenômenos históricos às intenções dos indivíduos (por essa razão, sem dúvida, o termo estratégia aparece muito raramente nas suas reflexões) (Schmidt 2003, 19).

Seguindo de perto Ítalo Calvino, Loriga se apropria de algumas reflexões autobiográficas do escritor italiano: na esperança de conferir um caráter representativo a uma história de vida, nós temos seguidamente a tendência a escolher os traços mais comuns e negligenciar os traços mais pessoais. O resultado desse trabalho é que o tempo histórico aparece como um pano de fundo fixo, sem impressões digitais. Seguindo essa lógica, a historiadora italiana afirma que seria um grande equívoco o cerne da chamada biografia modal, que não passaria de uma grande miragem tentar apreender uma época ou uma civilização reconstituindo seus elementos um por um. É a ideia de uma prosopografia completa, acabada. Esta perspectiva, fortemente utópica, contribuiria também para um esfacelamento perigoso da história e daria, assim, margem para a crítica realizada por Pierre Bourdieu.

De acordo com Loriga, Bourdieu escreveu seu artigo em uma polêmica com certos estudos de história oral que descreviam a vida de uma maneira excessivamente linear, como um caminho com um começo, algumas etapas e um fim. Nesse sentido, Loriga concorda plenamente com o sociólogo francês: limitar a existência à pesquisa de uma improvável unidade de sentido revela uma ingenuidade imperdoável, que a literatura do século XX não cessou de desvelar a natureza descontínua e provisória do real. Além disso, a intervenção crítica de Bourdieu foi, para ela, extremamente importante porque evidenciou os riscos de certa inconsciência ou preguiça 
metodológica na redescoberta das biografias feita pelas ciências sociais nas últimas décadas do século XX.

Entretanto, as concordâncias com Bourdieu terminam por aqui. Apesar de fundamental, segundo ela, a objeção de Bourdieu corre o risco de afirmar que o perigo de cair em uma história cronológica, factual e pouco problemática não está inscrito inevitavelmente na reflexão biográfica. Loriga afirma que tomar a experiência individual não significa sempre, automaticamente, adotar a forma tradicional da biografia (Loriga 1998, 246). E, ao contrário desse modelo biográfico, gênero literário baseado na unicidade da existência, a história busca reconstruir o tecido social e cultural. Nada impede que nós, historiadores, possamos utilizar a experiência individual para quebrar o excesso de coerência do discurso histórico, ou seja, para nos interrogarmos sobre a pluralidade e a incerteza do passado. E como bem lembrou Giovanni Levi, as vidas que se afastam da "média" talvez nos levem a refletir melhor sobre a tênue relação entre a especificidade do destino pessoal e o conjunto mais amplo do sistema social (Levi 1996).

É a partir dessa última reflexão que examinaremos agora o papel que a análise biográfica e das trajetórias individuais tiveram nas pesquisas de Cerutti e Gribaudi e que possibilitou a eles reconstruir suas visões sobre a História Social por meio da micro-história; história essa pautada na compreensão de grupos, instituições e sociedades através da análise dos atores históricos imersos em suas redes de interdependência.

\section{A biografia como chave para a compreensão de incertezas}

Tanto Maurizio Gribaudi quanto Simona Cerutti iniciaram seus estudos acadêmicos na Universidade de Turim e lá se tornaram alunos de Giovanni Levi. Além disso, Cerutti foi, juntamente com Levi e Carlo Ginzburg, uma das organizadoras da famosa coleção Microstorie, que reuniu alguns dos trabalhos que acabaram por definir os contornos da microstoria italiana. Apesar de terem trajetórias de pesquisa diversas, ambos percorreram uma careira acadêmica similar. Ainda hoje os dois são professores e diretores de estudos da École de Hautes Études em Sciences Sociales em Paris, sendo eventualmente coordenadores do Laboratoire de Démographie et d'Histoire Sociale (LaDéHiS).

É importante ressaltar que o conjunto das obras de Cerutti e Gribaudi foi recebido timidamente no debate historiográfico brasileiro. Na maior parte dos trabalhos que dialogam com esses autores, no que tange à riqueza da produção bibliográfica de ambos, percebemos uma apropriação, especialmente de seus textos publicados na coletânea intitulada Jogos de escala: a experiência da microanálise. Do ponto de vista metodológico, o trabalho de Cerutti tem sido 
retomado na discussão da pertinência da microanálise para estudos de caso e também para a reafirmação de que os grupos profissionais e sociais não podem ser descritos nem classificados antes mesmo de analisarmos o tecido das relações que eles forjaram por meio das suas redes de interdependência (Silveira 2010; Bonato 2011; Venancio 2018). Já a reflexão voltada para as pesquisas de Gribaudi aborda principalmente a discussão desse autor sobre a questão das escalas de análise micro e macro.

Apesar disso, os dois historiadores italianos foram apropriados numa discussão mais recente sobre os métodos para a construção da biografia como escrita da história (Venancio 2018 e Barreto 2009); como suporte teórico e metodológico para o estudo do sistema escravista brasileiro (Ferreira 2006; Fragoso 2010b; Matheus 2010; Moreira 2013), bem como da análise do chamado Antigo Regime dos Trópicos (Fragoso 2010a; Guedes 2016). Além disso, Osório, Farinatti, Kuhn, Reguera, Reis (Farinatti 2001, 2006 e 2008; Kuhn 2006; Reguera 2006; Reis 2008) dentre outros, utilizaram a reflexão de pelo menos um dos dois micro-historiadores para discutir o papel e usos das fontes cartoriais e da história serial para a compreensão dos grupos sociais e das suas redes de interdependência.

Por fim, é importante ressaltar que a obra de Gribaudi foi debatida também para a discussão das tendências da História do Trabalho no Brasil, sobretudo no que diz respeito à renovação dos estudos da classe trabalhadora utilizando as fontes orais e a sua relação crítica com a memória, de uma forma pouco usual no Brasil (Ferreras 2002). Neste caso, a apropriação de sua tese de doutorado (Gribaudi 1987) permitiu a aproximação da interpretação que os indivíduos, ou os grupos sociais, constroem suas próprias vidas e que esta percepção é confrontada com a realidade e com as transformações experimentadas pelas pessoas comuns.

Cerutti possui na Europa o status de umas das grandes historiadoras italianas da atualidade, sendo autora de uma obra referencial sobretudo do ponto de vista teóricometodológico, discutindo, dentre outras coisas, o estatuto das fontes judiciais e policiais e sua importância para a História Social. Em vários de seus textos ela discute também os elementos da microstoria a partir da obra de E. P. Thompson, um dos seus principais interlocutores nos anos 1990. Ao escrever seu livro A formação da classe operária inglesa, Thompson defendia algo que, para os historiadores atuais, pode parecer banal: estudar um processo, mais que um objeto. Nada era, todavia, menos óbvio nesse momento, no qual grande parte dos historiadores, entrincheirados em suas especializações, individualizavam seus objetos que remetiam apenas a campos distintos da vida social (Cerutti 1998). Apesar da dívida ao trabalho do historiador inglês, Cerutti abordou seus objetos numa perspectiva microanalítica (ao contrário de Thompson, cuja perspectiva, neste 
caso, era macro-histórica, segundo Cerutti) tentando levar até o fim as implicações de uma análise processual.

Apesar das similaridades com as perspectivas biográficas dos outros autores já citados ligados à micro-história, um dos elementos centrais das discussões biográficas de Cerutti foi questionar, ou mesmo superar, alguns elementos considerados redutores na análise thompsoniana, sobretudo no que diz respeito à experiência. Em Thompson, a experiência vivida pelos sujeitos históricos é única, mas é invariavelmente ditada pelas relações de produção nas quais eles estavam inevitavelmente inseridos. Isso, segundo a historiadora italiana, mantinha parte daquele determinismo econômico contra o qual Thompson tanto tinha lutado. Dito de outra forma, o determinismo foi atenuado, mas não ultrapassado (Cerutti 1998, 186).

Já Cerutti, fazendo uso de análises biográficas, como demonstramos em outro trabalho (Carneiro 2018a, 46-55), adotou procedimentos de análise de cunho mais processual: seu objeto foi analisado em seus componentes e relações recíprocas. Os indivíduos foram efetivamente situados em suas redes de obrigações, expectativas e reciprocidades fazendo com que o centro da análise fosse formado pelo processo social em análise. Observamos então uma reformulação fundamental da relação mantida entre o sujeito a ser biografado e suas redes de interdependência; temos assim uma complexificação do fazer biográfico inserido nos debates historiográficos próprios dos anos 1980 e 1990.

Em um livro mais recente (Cerutti 2012), Cerutti manteve suas perspectivas acerca do discurso biográfico, fazendo uso mais uma vez dos arquivos turinenses do século XVIII. Neste trabalho ela se interrogou sobre a noção de "estrangeiro", ou melhor, de forasteiro, já que o conceito não se aplica necessariamente a homens e mulheres originários de outros países. Ser estrangeiro seria, portanto, acima de tudo, sofrer de falta de pertença, independentemente do local de nascimento ou proveniência territorial. Os quatro capítulos do livro se apoiam neste postulado, ilustrando os diferentes contextos desta condição (hereditariedade, propriedade, profissão, justiça). Todas estas circunstâncias têm em comum, segundo a autora, a falta de integração, permanente ou temporária, voluntária ou imposta, nos tecidos sociais e nas redes estáveis de relacionamentos que dão acesso a certos recursos emblemáticos da cidadania urbana. Para Cerutti, a certidão de naturalização é apenas uma etapa necessária no tortuoso percurso de integração a um Estado.

No que diz respeito à questão biográfica, Cerutti retomou no segundo capítulo do livro supracitado a trajetória de um alfaiate chamado Girolamo Motta. Para tanto, ela fez uso de uma metodologia microanalítica para medir o papel da religião, mas também da propriedade, do crédito e das benesses nos processos de integração social e acesso à "cidadania". De acordo com 
a historiadora italiana, Girolamo Motta era alfaiate que chegou a liderar sua corporação no início do século XVIII. Todavia, a peculiaridade desta personagem é que ela aparece na documentação como sendo um "Turco da Anatólia", que, pelo nome, muito provavelmente se tratava de um muçulmano convertido. Infelizmente as fontes não nos mostram o lugar dessa eventual conversão ao catolicismo.

Da mesma forma, não é fácil entender, com os documentos disponíveis, como Motta conseguiu atingir esse nível de sucesso. Cerutti credita parte disso à proteção oferecida pelo Príncipe Eugênio (1663-1736), de espírito cosmopolita e aberto à discussão ecumênica. Isso talvez explicasse a promoção de Motta, que chegou a ser seu alfaiate pessoal, mas tal fato não nos ajuda, contudo, a elucidar as razões da instalação desse otomano em Turim na década de 1660, numa época em que o brilhante príncipe estrategista savoiano ainda era criança e protegido do rei da França.

Essas importantes lacunas biográficas, no entanto, não diminuem o escopo geral da demonstração da hipótese de Cerutti, nem da sua análise da trajetória do otomano. Segundo ela, naturalizado em 1699, a posição de Girolamo Motta é particularmente vantajosa devido à sua capacidade de manipular o dinheiro e de fazê-lo circular. Devido à sua posição de credor em relação a muitos comerciantes de Turim, mas também por suas doações para instituições de caridade (sobretudo o Hospital da Caridade), o alfaiate criou uma rede social e um enraizamento que lhe garantiu propriedade de terra e imóveis que, na época, não eram acessíveis legalmente a estrangeiros. Por isso, para a autora, é legítimo verificar o ápice de sua ascensão quando, em 1717, Motta conseguiu adquirir uma casa na cidade e um vinhedo em Castiglione.

Cerutti conseguiu demonstrar que não foi o acesso às propriedades que abriu ao turco da Anatólia as portas da cidadania, mas o contrário: foi a rede de relações e de interdependência que ele construiu que gerou o sucesso de uma integração formalizada, aí sim, na aquisição de imóveis. A compra de uma propriedade é, segundo ela, "tanto a prova quanto o símbolo de estabilidade e compartilhamento de interesses dentro do espaço urbano" (Cerutti 2012, 122). O raciocínio reforça a ideia desenvolvida no seu primeiro capítulo de que uma integração que não é feita apenas com base em simples operações "mecânicas" (naturalização ou acesso à propriedade), mas no desenvolvimento lento e resignado de redes estáveis (neste caso através da criação de um espaço de crédito) e influentes da cidade.

Ao ler este livro, alguém poderia se perguntar por que Simona Cerutti intitulou este capítulo "Étranger à la communauté des fidèles", já que os supostos antecedentes islâmicos de Motta são apenas hipotéticos até este ponto do texto. Fazendo uso da típica narrativa micro-histórica, Cerutti apresenta ao leitor o último testamento do alfaiate turco, redigido em 1724. Neste 
documento, ela fica surpresa com a ausência de qualquer menção às suas origens. Certamente este fato poderia ser um sinal adicional dessa integração, tão bem-sucedida que teria obscurecido as origens de Motta. Todavia, Cerutti não se rende a este raciocínio verossímil, mas sem fundamentação. A partir daí foi realizada uma análise extremamente detalhada do contexto de Turim que lhe permitiu desenvolver uma demonstração que podemos classificar como uma das mais belas ilustrações das potencialidades da microstoria italiana e de seus pressupostos heurísticos em geral. Além disso, essa investigação empírica pode ser vista como uma resposta aos elementos centrais da biografia modal: Cerutti, ao analisar a trajetória de uma figura específica, não a valoriza como ilustrativa de uma mentalidade coletiva que revelaria ao leitor o comportamento médio das categorias sociais.

No Estado savoiano da década de 1720, havia uma atmosfera de suspeita em relação a tudo o que não era católico, percebida pela instituição dos guetos judeus em 1723 e pela expulsão dos calvinistas entre 1722 e 1724 . Além disso, havia outra situação: tanto os alfaiates quanto os comerciantes de tecidos estrangeiros eram particularmente visados pelos fabricantes locais que, acusando-os de controlar o mercado de seda, acabaram por impor ao reino da Sardenha um forte protecionismo (proibição da livre circulação de tecidos de seda, mas também em lã e algodão).

Este contexto dá a extensão dos limites da integração nos Estado da Savóia e justifica claramente o "percurso catártico" da identidade de Girolamo Motta, às vezes clandestino e às vezes aparente. Assim, as origens de um indivíduo podem ser reativadas a qualquer momento, independentemente dos juramentos, conversões, sinais de adesão, dinheiro, prestígio e de proteções. Simona Cerutti conseguiu perceber através da análise desta trajetória a confirmação de como uma religião - o catolicismo - permanece como "um dos critérios mais sólidos de definição da cidadania nos países da Europa Ocidental". Ao analisar a trajetória de Motta por meio de uma metodologia ligada à micro-história italiana, Cerutti conseguiu escapar das armadilhas típicas, já analisadas anteriormente, da biografia modal.

Gostaria ainda de ressaltar que um dos propósitos centrais dos dois livros de Cerutti é mostrar que, apesar das similaridades de abordagens dos micro-historiadores acerca da questão biográfica, seus trabalhos foram produzidos, em alguns casos, em contextos historiográficos diferentes, procurando responder a perguntas diferentes. Cerutti não abordou, ou melhor, não construiu suas biografias coletivas da mesma forma que Gribaudi analisou as trajetórias dos trabalhadores franceses e italianos, nem se aprofundou em discutir teoricamente o estatuto da biografia, como fizeram Giovanni Levi e Sabina Loriga em momentos distintos. Se Cerutti tem como objetivo usar as biografias para questionar e ampliar as discussões que mostramos acima, 
Gribaudi, como veremos a seguir, possui outros objetivos, mas ainda inseridos nas preocupações dos micro-historiadores quando discutem e contribuem com o debate do desafio biográfico.

\section{Maurizio Gribaudi e a análise das trajetórias: uma micro-história benjaminiana}

Poucos historiadores são mais capacitados do que Maurizio Gribaudi em relação à produção de análises sobre a história da Paris popular da primeira metade do século XIX. Tendo se especializado em demografia e morfologia urbana, Gribaudi publicou, no fim dos anos 1980 (Gribaudi 1987), uma obra inovadora sobre a mobilidade dos operários de Turim no século XX, analisando, por meio da metodologia da network analysis e da obra de Barth, os elementos que levaram os operários desta cidade, antes socialistas, a abraçarem os ideários do fascismo nos anos 1940.

Mais recentemente, ele conduziu, juntamente com outros pesquisadores, uma reflexão coletiva ambiciosa, a um só tempo empírica e teórica, sobre os vínculos e as redes sociais nas quais os atores sociais se inscrevem, mas igualmente sobre as relações entre estruturas e dinâmicas sociais (Gribaudi 1998). Não podemos esquecer também da obra dedicada à revolução de 1848 (Gribaudi 2008), qualificada por ele como "esquecida", na qual analisa os mecanismos de apagamento deste evento em setores inteiros da historiografia francesa. Por fim, Gribaudi lançou, em 2014, uma obra sobre as formas de organização dos meios populares parisienses desde a Revolução Francesa até a Revolução de 1848 (Gribaudi 2014). Neste livro, Gribaudi sintetizou todos os métodos de pesquisa utilizados ao longo de uma carreira rica na produção de textos de referência, nos quais demonstrou a influência dos trabalhos e reflexões teóricas de autores como Giovanni Levi, Norbert Elias, Marc Bloch, Charles Tilly, Edward Shorter, Peter Laslett, J. Clyde Mitchel, A. L. Epstein, Jeremy Boissevain e Fredrik Barth.

No que diz respeito à discussão que estamos realizando aqui, em um artigo de 2001, Maurizio Gribaudi analisou a trajetória de quatro operários na França do século XIX (Gribaudi 2001). Por meio da leitura desses percursos operários, o historiador italiano concebeu a biografia não como um caminho compacto, cuja trajetória é determinada por poucas variáveis fundamentais e de intensidade estatisticamente definida, mas antes, buscou apreendê-la como a progressão de um organismo vivo e imerso no interior de um espaço que evolui e se transforma. Um elemento central nesta análise é que a relação indissociável de cada trajetória com a natureza do espaço social no qual elas se inserem pôde ser vista claramente através das biografias analisadas. 
Da forma como Gribaudi constrói metodologicamente as trajetórias, as personagens evocadas, desde o nascimento, se inscrevem no interior de configurações sociais que se caracterizam pelas modalidades de articular e utilizar uma gama específica de recursos, símbolos e memória (Carneiro 2018b). Ele percebeu, assim, como a sociedade francesa do século XIX era fragmentada pela presença de zonas marcadas por diferentes experiências sociais, dentro das quais não somente as perspectivas, mas, sobretudo, as possibilidades objetivas de cada indivíduo, podem variar drasticamente (Gribaudi 2001, 119).

Dialogando teoricamente com Warburg, Goethe e Benjamin, Gribaudi sugeriu a possibilidade de pensar a biografia não como um simples percurso linear que segue a todo momento uma mesma direção determinada sempre pelos mesmos fenômenos estruturais, mas sim como conjunção sempre incerta de inúmeros elementos em constante interação, sensíveis, ao mesmo tempo, a restrições locais e globais. Ele observou que cada presente histórico apresentado nas trajetórias de vida como uma massa borbulhante carregada de lembranças, tensões e aspirações contraditórias ${ }^{1}$.

A analogia mais precisa que pode ser usada para descrever essas dinâmicas é a de um sistema complexo de elementos em constante interação, revelando simultaneamente as sensibilidades locais e globais. Cada elemento é principalmente sensível ao seu ambiente local. Esse ambiente não é, por sua vez, sensível aos movimentos de conjunto do qual é necessariamente uma pequena parte. Desta maneira, cada mudança em qualquer ponto dessa configuração implica, portanto, numa redefinição mais ou menos importante de todos os elementos que compõem esta configuração. Em cada momento, cada um dos elementos do sistema reatualiza sua posição e seu conteúdo em função das mudanças que ocorrem paralelamente à sua própria trajetória (Gribaudi 2018, 2).

Assim, Alexis e Bertrand, dois dos operários cuja trajetória foi analisada, apesar de abandonarem, quase com a mesma idade, os seus vilarejos para emigrarem para Paris e morarem a poucas centenas de metros de distância um do outro, vivenciaram e se desenvolveram em duas sociedades totalmente separadas e, entre si, incomunicáveis. Cada um deles viveu em uma França diferente, estruturada a partir das suas práticas e das suas emoções, e pelas relações de força que se estabelecem dentro do espaço mais vasto. Para apreender os sentidos de tais percursos e experiências sociais foi necessário reconstruir a geografia desses espaços, inventariar a gama de elementos que os compõem, medir a sua consistência e identificar suas proximidades com outros espaços, outras zonas de coerência.

\footnotetext{
1 Agradeço imensamente a Maurizio Gribaudi pela gentileza de me enviar uma cópia do texto utilizado nessa conferência (Gribaudi 2018).
} 
Para Gribaudi, um percurso individual se apresenta como o desenvolvimento de um ser orgânico totalmente imerso no espaço social e determinado pelas relações ali presentes. A identidade é apreendida não como um estado determinado a partir de uma origem ou adquirido ao final de um percurso, mas, acima de tudo, nos termos de um processo no curso do qual há mudanças não somente do indivíduo, mas também do espaço social no qual ele se inscreve. Ao não cair no erro de tomar o indivíduo e o contexto como duas entidades separadas, Gribaudi apreende a natureza do espaço social através dos usos concretos feitos pelos indivíduos que o compõem. O indivíduo e o espaço social evoluem e se modificam mutuamente, sendo um parte do outro (Gribaudi 2001, 117).

Tal perspectiva convida o historiador a pensar o espaço social não tanto por meio de um conceito de estrutura coerente e funcional, mas sobretudo utilizando imagem de uma constelação de pontos em tensão, portanto instáveis, movendo-se a cada momento de maneiras diferentes. $\mathrm{O}$ significado de um presente histórico, de acordo com Warburg, é dado pela natureza dos sincretismos temporais que o caracterizam (Gribaudi 2018, 6).

Assim, os acontecimentos que se seguem e que dão ritmo à história dos biografados por Gribaudi revelam lógicas análogas, adquirindo o seu significado específico dentro da configuração global das relações, das memórias e das aspirações, na qual se desenvolve. Mas, ao mesmo tempo, cada novo acontecimento e cada nova relação induzem a um reajuste contínuo do conjunto e modificam, portanto, a condução dos elementos presentes (Gribaudi 2001, 124). É uma configuração ao mesmo tempo individual e social. Individual, já que se trata de uma série de experiências, de memórias e de relações que se consolidaram sobre a base de vivências e das emoções, as quais marcam e orientam, no presente, as práticas e a construção de seus projetos de vida. Social, porque os recursos utilizados, as relações iniciadas, as referências e os símbolos presentes pertencem, todos, a um espaço de relações atravessado e estruturado por vivências análogas.

Essa força estruturante da experiência social, que constantemente se reatualiza e que vai transformando os sistemas de coerência individuais e de grupo é, para o historiador italiano, um elemento central para a compreensão das dinâmicas históricas. Ela nos permite tanto apreender o desenvolvimento de cada configuração, das redes de interdependências recíproca e de cada prática social, quanto explicar as transformações de perspectivas que podem ser observadas no desenvolvimento de uma vida, de um grupo ou de uma sociedade (Gribaudi 2001, 145-146).

É importante destacar que as experiências sociais dos biografados apresentam a possibilidade de novas conexões. Isso ocorre tanto pela inserção das experiências em uma série de conexões, de imagens e representações já existentes, quanto, eventualmente, pela 
reorganização, sob uma nova forma, dos elementos presentes dentro de uma velha configuração, de um conjunto estrutural, que pode parecer melhor e mais coerente. Essa reconfiguração pode tornar-se global e abrir perspectivas de ações drasticamente novas para o indivíduo, o grupo ou a sociedade que passe por essa experiência. Desta maneira, o percurso individual aparece não como uma trajetória linear, mas como uma série de deslocamentos e de reajustes de um enorme emaranhado de relações, experiências, lembranças e imagens reunidas em torno de um ponto de uma dessas zonas sociais (Gribaudi 2001,145-146).

Seguindo de perto as reflexões de Walter Benjamin, Gribaudi nos sugeriu pensar a historicidade como uma constelação de diferentes elementos que formam, em sua relação recíproca, uma coerência única e específica. Desta maneira, o caráter e a especificidade de um presente histórico são dados pelas modalidades de manter coerências diversas e muitas vezes contraditórias. Assim, em sua dimensão temporal, a história seria, portanto, fundamentalmente caracterizada pela descontinuidade, e não pela continuidade. Para o historiador italiano, a evolução e a continuidade formal do espaço social seria apenas aparente. A cada momento, suas formas reatualizariam seus conteúdos inseridos em um movimento simultâneo.

Isto traria aos historiadores implicações importantíssimas: tudo que nós herdamos do passado deve ser atualizado, inscrito e ancorado na sempre nova configuração de símbolos, imagens, objetos, práticas, aspirações e conjunto de elementos que formam o horizonte dos presentes históricos. Cada um dos presentes que se desdobram à frente da história está inscrito em inúmeras temporalidades, por meio de inúmeras referências, memórias ou representações do passado, assim como inumeráveis antecipações do futuro percebidas pelos contemporâneos como possíveis. Temos em Gribaudi uma peculiaridade em relação aos outros microhistoriadores: o resgate da visão da História de Walter Benjamim como uma ferramenta fundamental para a construção de pesquisas ligadas à micro-história e para a produção de biografias complexas e distantes da perspectiva modal.

Nessa perspectiva, nenhum elemento do desenvolvimento da vida dos biografados aparece como determinado a priori. A cada momento, vários futuros são considerados, concebíveis e percebidos como realmente praticáveis. É por isso que Gribaudi afirma que o presente não é apenas uma questão de historicidade, mas é também uma chave, um momento de bifurcação onde estão em jogo as formas possíveis do desenvolvimento histórico. Não se trata de construir uma narração dos acontecimentos históricos, ou, nesse caso, da vida e das trajetórias dos sujeitos biografados, mas de reconstruir, por uma técnica próxima à da "montagem", a topografia das tensões que animam o coração da história (Gribaudi 2018, 2 e 14). 


\section{Considerações finais}

Parte da discussão que travamos aqui pode ser vista como uma continuação das reflexões que realizamos sobre a mesma temática em um texto de 2018 (Carneiro 2018a). Neste primeiro texto, analisamos especialmente os usos da biografia no livro inaugural de Simona Cerutti e o inserimos nas grandes discussões historiográficas acerca do ressurgimento do sujeito como agente histórico, típicas da segunda metade do século XX. A ênfase que o debate sobre a biografia revelava era a criação de uma nova modalidade de História Social que permitiria a reformulação da relação existente entre as normas e os comportamentos; percebendo a multiplicidade de interações do indivíduo e enxergar, dentro de um debate mais amplo, um sujeito que atua em inúmeras esferas sociais. Parcialmente livre das amarras de uma estrutura estruturante, este sujeito, com inúmeras escolhas, possibilidades e estratégias, lidaria com as múltiplas interações que sua rede de interdependências lhe possibilitaria, alterando e construindo a própria estrutura.

Todavia, mostramos nesse artigo que não podemos ler as contribuições de todos os micro-historiadores da mesma maneira. As perspectivas biográficas de Levi e Grendi, por exemplo, devem ser vistas de uma maneira mais ampla, ou seja, como questionamentos aos paradigmas exploratórios de escala macro. Seus alvos eram o marxismo vulgar, a longa duração braudeliana, as abordagens inerentes à história quantitativa e os modelos funcionalistas e estruturalistas. E, como resposta a esses modelos, privilegiaram o uso intensivo de fontes primárias (especialmente documentos cartoriais, fontes jurídicas e autobiografias) em uma abordagem sincrônica para desvelar a interconexão entre fenômenos múltiplos que identificam processos causais de mudança. Dialogando com antropólogos, tais como Karl Polanyi, Fredrik Barth e J. Clyde Mitchel, colocaram no centro de suas análises questionamentos sobre o funcionamento da racionalidade humana que governa os comportamentos individuais e sociais.

De todos os micro-historiadores, Loriga foi aquela que mais se ocupou com as reflexões teóricas sobre a legitimidade e o papel da biografia, respondendo adequadamente à provocação de Pierre Bourdieu não só ao estatuto da biografia, mas também ao da própria História enquanto disciplina. Seja em sua análise prosopográfica dos soldados do Piemonte (Loriga 2007), seja em seu pequeno $\times$ (Loriga 2011), Loriga demostrou uma lição cara à micro-história: é impossível compreender o biografado sem apreendermos suas ações e seu posicionamento em suas redes de relações recíprocas.

Já a perspectiva biográfica de Cerutti continua de alguma maneira inserida no debate dos anos 1980 e 1990, muito longe, entretanto, do debate francês sobre as pertinências da biografia. 
A historiadora italiana dialoga direta e indiretamente com pressupostos clássicos da sociologia em sua versão thompsoniana: está preocupada com os conceitos de ação, agência e experiência; preocupada em compreender a formação e ação dos grupos não de forma estruturante nem determinada, mas de compreender o grupo como fruto das interações interdependentes do sujeito e de questionar o uso apriorístico de conceitos como grupo e classe. Apesar de inserida em um debate de mais de 30 anos, esta perspectiva continua importante e renovada nas discussões da História Social, assumindo agora perspectivas ligadas à Social Network. Analysis.

Em relação às reflexões de Gribaudi sobre as trajetórias individuais e de grupos, percebemos que essas possuem certas peculiaridades em relação às outras contribuições da micro-história para o debate. Apesar de seu livro de 1987 estar evidentemente inserido nas preocupações biográficas discutidas por Levi e Cerutti, seu artigo de 2001 lhe permitiu pensar a experiência individual em toda a sua particularidade como parte indissociável de um contexto e da natureza pluridimensional do espaço social ${ }^{2}$.

As experiências dos sujeitos históricos se inscrevem e adquirem significados dentro de um horizonte social no qual são interpretadas formas específicas de combinar símbolos, recursos, lembranças e expectativas etc. Ao dialogar sobretudo com Walter Benjamim, Gribaudi percebeu a complexidade das múltiplas temporalidades que atingem o sujeito e os grupos sociais. Segundo ele, em cada um dos vários presentes estão inseridos incontáveis referências aos passados e inumeráveis projeções de futuro, ou seja, o presente é sempre tensionado pelas memórias do que foi o passado e pelas contraditórias possibilidades de futuro; que aquilo que herdamos do passado é apenas um solo fértil a partir do qual se engendram formas e práticas (Gribaudi 2018, 2-6).

Compreendendo o presente como uma mistura particular de sobrevivências e antecipações, Gribaudi se utiliza também da análise das trajetórias como forma de entender o processo histórico, que para ele é um sistema que desdobra suas formas mantendo certa estabilidade, mas que também pode se modificar drasticamente em qualquer momento, quando as tensões presentes induzem a uma reconfiguração das relações dentro dos elementos físicos e simbólicos que formam a constelação de um presente histórico. Em resumo, Gribaudi leva a discussão biográfica microanalítica a outros patamares, numa espécie de radicalização dos pressupostos de Levi e Grendi.

Por fim, é importante ressaltar que, ao analisarmos as múltiplas contribuições de historiadores ligados à micro-história italiana, fica claro aquilo que todos os especialistas nessa

\footnotetext{
2 Para visualizar a aplicação dessas questões em um trabalho empírico de fôlego, indico a leitura de Gribaudi (2014).
} 
corrente historiográfica têm dito desde o século passado: a micro-história não é uma escola no sentido que damos à Escola dos Annales; os diálogos e referências teóricas aqui são múltiplos. E nisso está uma das maiores forças dessa corrente, qual seja, revelar um indivíduo relacional e complexo, cuja trajetória ou biografia, dependendo da situação, é fundamental para a compressão da realidade, entendida como a configuração resultante das inúmeras redes de interdependência dos atores sociais e interpolações de múltiplas temporalidades.

\section{Referências bibliográficas}

Ago, Renata. "From the archives to the library and back: culture and microhistory". Em Between Sociology and History. Essays on Microbistory, Collective Action, and Nation-Building, org. A. M. Castrén, M. Lonkila e M. Peltonen.41-50. Helsinki: SNK, 2004.

Barreto, Adriana. "Experiência, configuração e ação política: uma reflexão sobre as trajetórias do duque de Caxias e do general Osório". Topoi, 10, n. 19 (2009). https://doi.org/10.1590/2237101X010019006

Bonato, Massimo. 2011. "A Micro-história e o método da história de vida”. Anais do XXVI Simpósio Nacional de História - ANPUH, São Paulo, Brasil, 2011.

Bourdieu, Pierre. "A ilusão biográfica”. Em Usos e abusos da História Oral, Ferreira, Marieta Morais Ferreira e Janaina Amado. 183-192. Rio de Janeiro: EdFGV, 2006.

Carneiro, Deivy F. "Micro-História e História do Crime e da Justiça Criminal: um diálogo possível e desejado”. Em Crime e Justiça: reflexões, fontes e possibilidades de pesquisa, org. Maíra I. Vendrame, Cláudia Mauche e Paulo R. S. Moreira. 33-66. São Leopoldo: Editora Unisinos, 2018b.

Carneiro, Deivy F. "Os usos da biografia pela micro-história italiana: interdependência, biografias coletivas e network analysis". Em O que pode a biografia, org. Alexandre Sá Avelar e Benito Bisso Schmidt, 33-58. São Paulo: Letra \& Voz, 2018.

Cerutti, Simona. "Langage des acteurs, langage des historiens : de quoi parlent les sources judiciaires ?’. L'Atelier du Centre de recherches historiques, 05 (2009). https://doi.org/10.4000/acrh.1645

Cerutti, Simona. ““A rebrousse-poil'. Dialogue sur la méthode”. Critique, 769-770 (2011): 564-575. https://doi.org/10.3917/criti.769.0564

Cerutti, Simona. "Processo e experiência: indivíduos, grupos e identidades em Turim no século XVII". Em Jogos de Escalas: a experiência da microanálise, org. Jacques Revel. 173-202. Rio de Janeiro: Editora da FGV, 1998.

Cerutti, Simona. "Faits et 'faits judiciaires'. Changements dans le statut de la preuve à Turin au XVIIIE siècle". Cahiers du Centre des Recherches Historiques, 45 (2010): 151-180. https://doi.org/10.4000/ccrh.3566

Cerutti, Simona. "Normes et pratiques, ou de la légitimité de leur opposition". Em Les formes de l'expérience. Une autre histoire sociale, org. B. Lepetit. 175-204. Paris : Découvert, 1995.

Cerutti, Simona. “Travail, mobilité et légitimité : suppliques au roi dans une société d'Ancien Régime (Turin, XVIIIe siècle)”. Annales Histoire, Sciences Sociales, 65, 3 (2010): 571-611. 
https://doi.org/10.1017/S0395264900040798

Cerutti, Simona. Étrangers : étude d'une condition d'incertitude dans une société d'Ancien Régime. Paris: Bayard, 2012.

Cerutti, Simona. "Histoire pragmatique, ou de la rencontre entre histoire sociale et histoire culturelle”. Tracés, n. 15 (2008): 147-168. https://doi.org/10.4000/traces.733

Cerutti, Simona. "Who is below ? E. P. Thompson, historien des sociétés modernes : une relecture". Annales. Histoire, Sciences Sociales, 70, 4 (2015): 931-956.

https://doi.org/10.1353/ahs.2015.0167

Dosse, François. O desafio Biográfico: escrever uma vida. São Paulo: Edusp, 2009.

Duby, George. Guilherme Marechal on o melhor cavalheiro do mundo. Rio de Janeiro: Paz e Terra, 2002.

Farinatti, Luiz Augusto E. "Construção de séries e micro-análise: notas sobre o tratamento de fontes para a história social”. Anos 90, 15, n.28 (2008a). https:/ /doi.org/10.22456/1983201X.7958

Farinatti, L. A. E. "Escravos do pastoreio: pecuária e escravidão na fronteira meridional do Brasil (Alegrete, 1831-1850)". Ciência \& Ambiente, v. 1 (2006).

Farinatti, L. A. E. "Para além de estancieiros e colonos: o Rio Grande do Sul rural dos oitocentos e os lavradores nacionais". Em Historiadores do novo Século, org. Júlio Quevedo. 1 ed. 45-73. São Paulo: Companhia Editora Nacional, 2001.

Farinatti, L. A. E. "Peões de estância e produção familiar na fronteira sul do Brasil (1845-1865)". Anos 90, v. 15, (2008b). https://doi.org/10.22456/1983-201X.6749

Febvre, Lucien. Martinho Lutero, um destino. São Paulo: Editora três estrelas, 2012.

Febvre, Lucien. O problema da incredulidade no século XVI: a religião de Rabelais. São Paulo: Cia. das Letras, 2009.

Ferreira, Roquinaldo. "Biografia, Mobilidade e cultura Atlântica: a micro-escala do tráfico de escravos em Benguela, séculos XVIII-XIX”. Tempo, Revista do Programa de Pós-Graduação da Universidade Federal Fluminense, Rio de Janeiro: UFF, 10, n. 20 (2006). https://doi.org/10.1590/S1413-77042006000100003

Ferreras, Norberto. "História e Trabalho: entre a renovação e a nostalgia”. Revista Trajetos, 1, n. 2 (2002).

Fragoso, João, e Maria de Fátima Gouvêa, org. Na Trama das Redes: politicas e negócios no império português, séculos XVI-XVIII. Rio de Janeiro: Civilização Brasileira, 2010a.

Fragoso, João. "Afogando em Nomes: temas e experiências na história econômica". Topói, 5, n. 5 (2002). https://doi.org/10.1590/2237-101X003005002

Fragoso, João. "Efigênia angola, Francisca Muniz forra parda, seus parceiros e senhores:

freguesias rurais do Rio de Janeiro, século XVIII. Uma contribuição metodológica para a história colonial”. Topói, 11, n. 21 (2010b). https://doi.org/10.1590/2237-101X011021005

Gandelman, Luciana Mendes. “Trajetórias individuais no Império português do século XVII: o caso do financista João de Mattos de Aguiar”. Em Sujeitos na história: perspectivas e abordagens, org. Gisele Venancio e Larissa Viana. 61-82. Rio de Janeiro: EDUFF, 2018.

Giulli, Mateo. "Morfologia Social e contextualização topográfica: a micro-história de Edoardo Grendi”. Revista Brasileira de História. 37, n. 76 (2017). https://doi.org/10.1590/1806-

93472017v37n76-07 
Grendi, Edoardo. Balbi: una famiglia genovese fra Spagna e Impero. Torino: Einaudi, 1997.

Gribaudi, Maurizio. 1848 - La révolution oubliée. Paris : La Découverte, 2008.

Gribaudi, Maurizio. Escala, Pertinência, Configuração. Em Jogos de escalas: a experiência da microanálise, org. Jacques Revel. 121-150. Rio de Janeiro: EdFGV, 1998.

Gribaudi, Maurizio. 2018. "Forma, tensão, movimento: a plasticidade da História". Conferência apresentada no III Simpósio Internacional Micro-História, trajetória e imigração, São Leopoldo, Unisinos, 2018.

Gribaudi, Maurizio. Itinéraires ouvriers : espaces et groupes sociaux à Turin au début du XXe siècle. Paris: Éditions de l'EHESS, 1987.

Gribaudi, Maurizio. Paris, ville ouvrière : une histoire occultée. 1789-1848. Paris : La Découverte, 2014.

Gribaudi, Maurizio. "Percorsi individuali ed evoluzione storica: quattro percorsi operai attraverso la Francia dell'Ottocento". Quaderni Storici, 36, n. 106 (1) (2001).

Guedes, Roberto, e João Fragoso. História Social em Registros Paroquiais: sul e sudeste do Brasil, séculos XVIII e XIX. Rio de Janeiro: Mauad X, 2016.

Kuhn, Fabio. "Gente da fronteira: família, sociedade e poder no sul da América Portuguesa século XVIII". Tese de doutoramento, Niterói, Universidade Federal Fluminense, 2006.

Levi, Giovanni. Herança Imaterial: trajetória de um exorcista no Piemonte do século XVII. Rio de Janeiro: Civilização Brasileira, 2000.

Levi, Giovanni. "Usos da biografia". Em Usos e abusos da história oral, org. Janaína Amado e Marieta de Moraes Ferreira. 167-182. Rio de Janeiro: Editora da FGV, 1996.

Loriga, Sabina. "A biografia como problema”. Em Jogos de escalas: a experiência da microanálise, org. Jacques Revel. 225-250. Rio de Janeiro: EdFGV, 1998.

Loriga, Sabina. O pequeno X: da biografia à história. São Paulo: Autêntica, 2011.

Loriga, Sabina. Soldats : un laboratoire disciplinaire - l'armée piémontaise au XVIIIème siècle. Paris : Belles Lettres, 2007.

Matheus, Marcelo Santos. "Por ter ido ao Estado Oriental: guerra e fronteira nas cartas de alforria de Alegrete (1832 - 1871)". VIII Mostra de Pesquisa do Arquivo Público do Estado do Rio Grande do Sul, Porto Alegre, CORAG, 2010.

Moreira, Paulo Roberto S., e Marcelo Santos Matheus. "A microanálise como suporte teóricometodológico para o estudo do sistema escravista brasileiro a partir da reconstituição de trajetórias de escravos (Alegrete, século XIX)". Revista CLIO - Revista de Pesquisa Histórica, 28, n.2 (2013).

Osório, Helen. O Império Português no Sul da América: estancieiros, lavradores e comerciantes. Porto Alegre: Editora da UFRGS, 2007.

Reguera, Andréa. Patrón de estancias. Ramón Santamarina: uma biografia de fortuna y poder en la pampa. Buenos Aires: EUDEBA, 2006

Reis, João José. Domingos Sodré. Um sacerdote africano: escravidão, liberdade e candomblé na Babia do século XIX. São Paulo: Cia. das Letras, 2008.

Revel, Jacques. A biografia como problema historiográfico. Em História e historiografia: exercícios críticos, org. Jacques Revel. 24-48. Curitiba: Editora UFPR, 2010.

Rizzini, Irma. "Pesquisa histórica dos internatos de ensino profissional: revendo as fontes produzidas entre os séculos XIX e XX”. Revista Contemporânea de Educação, 4, n. 7 (2009). 
Santos, Marilia Nogueira. "Privilégios institucionais ou individuais? Vice-reis da Índia e governadores-gerais do Brasil nos séculos XVII e XVIII". Em Sujeitos na história: perspectivas e abordagens, org. Gisele Venancio e Larissa Viana. 83-102. Rio de Janeiro: EDUFF, 2018.

Schmidt, Benito Bisso. Entrevista com Sabina Loriga: a História Biográfica. MÉTIS: história \& cultura. v. 2, n. 3, (2003).

Schmidt, Benito Bisso. "Entrevista com Sabina Loriga: a História Biográfica”. MÉTIS: história \& cultura, 2, n. 3 (2003).

Silveira, Eder da Silva. "Estudo de caso e Micro-História: distanciamentos, características e aproximações”. Revista História em Reflexão, 4, n. 8 (2010).

Trivellato, Francesca. "Is There a Future for Italian Microhistory in the Age of Global History?", California Italian Studies, 2 (1) (2011).

Venancio, Gisele, e Larissa Viana. Sujeitos na História : perspectivas e abordagens. Rio de Janeiro : EDUFF, 2018.

Recebido: 28 de agosto de 2019

Aprovado: 18 de outubro de 2019 